J. Lake Sci. (湖泊科学), 2014, 26(1): 19-28

http : //www. jlakes. org. E-mail : jlakes@niglas. ac.cn

(c) 2014 by Journal of Lake Sciences

\title{
太湖水体氮素污染状况研究进展
}

吴雅丽 ${ }^{1,2}$, 许 海 $^{1 * *}$,杨桂军 ${ }^{2}$, 朱广伟 $^{1}$,秦伯强 ${ }^{1}$

( 1 : 中国科学院南京地理与湖泊研究所湖泊与环境国家重点实验室,南京 210008)

( 2 : 江南大学环境与土木工程学院,无锡 214122)

摘 要: 氮是引起湖泊富营养化的关键要素之一. 传统观点认为氮缺乏时, 湖泊生态系统可以通过生物固氮作用从大气 中获取氮来满足自身的需求, 因此认为淡水湖泊水体的生产力主要受磷限制. 但随着进一步的研究, 发现氮限制与氮和 磷共同限制更为普遍, 且氮的限制常常伴随着水体的富营养化, 因此了解富营养化湖泊水体的氮素污染状况具有重要意 义. 本文介绍了太湖水体氮素的污染状况及其发展趋势, 从外源、内源两大方面介绍了太湖水体中氮素的来源, 着重分析 和比较了河道输人、大气输人以及沉积物释放不同污染源的输人比例. 太湖水体氮素污染存在很大的空间差异, 其中西 部和北部污染较重而东南部相对较轻, 人湖河道输人的外源污染是造成太湖水质空间分布差异的主要原因, 其中农业面 源污染及生活污染在太湖外源污染中占据了相当的比重; 湖泊底泥所造成的内源释放也是氮素污染的一个重要原因, 但 目前对释放量的估算主要是基于底泥悬浮引起的总量估算, 关于这些释放量能有多少比例可以被浮游植物利用还不清 楚, 尤其是有机颗粒物在水体中停留期间的矿化再生值得进一步研究; 在氮素的生物转化过程中, 生物固氮目前对太湖 氮素输入的贡献很小, 反硝化作用是太湖水体氮素自净的主要途径.

关键词: 太湖;氮素;污染来源;迁移转化;氮素平衡

\section{Progress in nitrogen pollution research in Lake Taihu}

WU Yali ${ }^{1,2}$, XU Hai ${ }^{1}$, YANG Guijun ${ }^{2}$, ZHU Guangwei ${ }^{1} \&$ QIN Boqiang ${ }^{1}$

(1: State Key Laboratory of Lake Science and Environment, Nanjing Institute of Geography and Limnology, Chinese Academy of Sciences, Nanjing 210008, P. R. China)

(2: School of Environment and Civil Engineering, Jiangnan University, Wuxi 214122, P. R. China)

Abstract: Excessive nitrogen loading has been regarded as one of the most important factors causing eutrophication of lakes. The traditional views show that when nitrogen deficiency occurs, lake ecosystems can obtain nitrogen from the atmosphere through biological nitrogen fixation to meet their nitrogen needs, so according to this assumption, the main limiting factor of the primary productivity of water bodies is phosphorus availability. However, recent research has shown that nitrogen fixation does not meet ecosystem demands, and nitrogen or nitrogen and phosphorus limitation are generally accepted. Furthermore, eutrophic lakes often exhibit nitrogen limitation, meaning that they are sensitive to additional nitrogen inputs. In this paper, research on the polluting effects of nitrogen in Lake Taihu was reviewed. Both the internal and external loadings of nitrogen to the lake were considered. The nitrogen inputs from the three main sources, i. e. input from rivers, precipitation from atmosphere and release from sediments, were analyzed. The results show that there is obvious spatial heterogeneity in nitrogen pollution of Lake Taihu. The pollution is relatively heavy in the western and northern parts of the lake and relatively light in the southeastern part. River input is a major source of nitrogen loading to the lake. Internal loading is also an important source of nitrogen pollution. However, to release a quantity estimate is mainly based on the amount of sediment resuspension, and about the release quality, how many percentage can be used by phytoplankton is still not clear, especially the particulates mineralization rates. The cycling nitrogen in lakes mostly mediate by ni-

* 国家自然科学基金项目 (41003043)、国家水体污染控制与治理科技重大专项项目 (2012ZX07101-010)、中国科学 院南京地理与湖泊研究所 “一三五”重点项目 (NIGLAS2012135005)、江苏省自然科学基金项目 (BK2012895) 和青 年启动基金项目 (Y1SL011025) 联合资助. 2012-11-12 收稿;2013-06-14 收修改稿. 吴雅丽(1987～), 女, 硕士 研究生;E-mail:wuyali0823@163.com.

** 通信作者;E-mail:hxu@ niglas. ac. cn. 
trification, denitrification, nitrogen fixation and anammox. In Lake Taihu, the process of biological nitrogen fixation has been found to contribute little to the total annual input of nitrogen and denitrification is the main process through which nitrogen is removed from the lake.

Keywords: Lake Taihu; nitrogen; pollution source; migration and transformation; nitrogen balance

随着工农业生产的快速发展、人口的急剧增加、化学肥料使用量的增加以及生活污水的直接排放, 河 流、湖泊等地表水体的氮、磷元素污染日趋严重. 研究表明, 目前我国 66\% 以上的湖泊、水库处于富营养化的 水平, 其中重富营养和超富营养的占 $22 \%$, 使得富营养化成为我国湖泊目前与今后相当长一段时期内的重 大水环境问题 ${ }^{[1]}$. 太湖是我国第 3 大淡水湖, 对周边居民的生产生活起着至关重要的作用. 但近几十年来, 由于受到人类活动的干扰加剧, 湖区水体富营养化程度加重, 蓝藻水华频繁发生, 给环境和经济造成了严重 的威胁 ${ }^{[2]}$.

1970s, Schindler 根据加拿大实验湖区 227 号湖长期的大规模实验结果, 认为磷是淡水湖泊主要的限制 因子 ${ }^{[3]}$, 该研究结果使 “削减磷负荷” 成为北美和欧洲进行湖泊管理的主要策略, 并由此提升了水质. 但此项 策略的实施也出现了大量失败的例子, 如仅控制磷的策略在美国的 Apopka 湖、George 湖和 Okeechobee 湖, 中国东湖及日本的霞浦湖似乎都未获得成功 ${ }^{[4]}$. 由此,生命活动的另一基本元素氮引起了科学家的重视, 氮 也是引发水体富营养化的关键元素之一. 有研究表明, 在许多湖泊中无机氮的消耗伴随而来的是固氮蓝藻 “水华” 的发生 ${ }^{[5-7]}$. 新近的很多研究显示, 在一些淡水湖泊中, 氮也是限制因子 ${ }^{[8.9]}$, 而且氮的限制常常伴随 着水体的富营养化 ${ }^{[10]}$. 在我国, 大量的研究也表明,氮或氮和磷是湖泊水体生产力的限制因子 ${ }^{[11-13]}$.

近年来, 随着流域工农业的迅速发展, 太湖水体富营养化日趋严重, 蓝藻水华暴发频繁. 过去, 在对太湖 水体富营养化研究中得到的结论是: 光和磷是主要的限制性因素, 氮不是太湖的限制因子. 但新近在太湖梅 梁湾开展的营养盐富集原位实验显示, 春季磷是浮游植物生长的限制因子, 氮是充分的 ${ }^{[14]}$; 而在蓝藻水华多 发的夏季和秋季, 氮和磷是蓝藻水华生长的共同限制因子, 并且氮是第一限制因子 ${ }^{[15]}$. 此时湖泊中水华蓝藻 群落仍以不具备固氮能力的微囊藻为主, 而不是具有固氮能力的种属占优势. 因此, 太湖水体或许还有其它 氮源补充途径, 能够快速补充藻类生长所需的氮素.

本文重点对太湖水体中氮素污染的总体状况、不同形态氮的空间及季节差异性、水体氮素的污染来源、 氮素的迁移转化及平衡等进行综述, 有利于正确认识太湖水体中氮素的来源和污染状况, 为有效控制太湖 蓝藻水华提供参考.

\section{1 太湖水体氮素污染状况}

\section{1 太湖水体氮素污染的长期趋势}

太湖在早期污染程度较低, 随着经济的发展, 污染速度逐渐加快. 太湖在 1960 年仍处于贫营养阶段, 总 无机氮 (TIN) 浓度为 $0.05 \mathrm{mg} / \mathrm{L}^{[16]}$, 到 1981 年, TIN 比 1960 年增加了 18 倍, 达 $0.89 \mathrm{mg} / \mathrm{L}$, 已经呈中营养状 态 ${ }^{[17]}$. 太湖在 1987 年左右进入富营养化阶段, TIN 浓度达到 $1.26 \mathrm{mg} / \mathrm{L}, 1990 \mathrm{~s}$ 后富营养化日趋加剧, 且速度 越来越快. 太湖治理从 1990s 后期得到了高度重视, 1998 年底对重点污染工业实施的 “零点达标行动” 使流 域污染物的输人得到一定控制 ${ }^{[18]}$. 但从 2000 年以来太湖并没有进入明显的水质恢复期, 反而呈现出一定的 恶化趋势. 有研究显示, 1992-2001 年, 太湖湖心区夏季水体总氮 ( TN) 的平均值为 $1.706 \mathrm{mg} / \mathrm{L}$ (范围为 $1.238 \sim 2.266 \mathrm{mg} / \mathrm{L}$ ), 而 $2002-2006$ 年这 5 年间 TN 平均值为 $2.344 \mathrm{mg} / \mathrm{L}$ (范围为 $1.924 \sim 2.717 \mathrm{mg} / \mathrm{L}$ ), 明 显高于前 10 年的含量 ${ }^{[19]}$.

太湖污染源所携带的氮负荷以溶解态为主, 占 $80 \%$ 以上, 其中无机氮又占可溶性氮的 $80 \%$ 以上, 说明外 源性 TN 中有 $64 \%$ 以上的氮可作为浮游植物等水生生物生长的氮源 ${ }^{[15]}$. 太湖水体溶解态氮主要以硝态氮 $\left(\mathrm{NO}_{3}^{-}-\mathrm{N}\right)$ 、溶解态有机氮 $(\mathrm{DON})$ 、铵态氮 $\left(\mathrm{NH}_{4}^{+}-\mathrm{N}\right)$ 形态存在, 一般情况下, $\mathrm{NO}_{3}^{-}-\mathrm{N}>\mathrm{DON}>\mathrm{NH}_{4}^{+}-\mathrm{N}$, 而亚硝态 氮 $\left(\mathrm{NO}_{2}^{-}-\mathrm{N}\right)$ 含量很低且不稳定, 易转化为其它形态的氮 ${ }^{[20]}$. 朱广伟 ${ }^{[21]}$ 分析了太湖湖泊生态系统研究站 2005 年 1 月至 2007 年 3 月的监测数据, 发现太湖水体溶解态氮平均占水体总氮的 $79 \%$, 且以 $\mathrm{NO}_{3}^{-}-\mathrm{N}$ 污染为主.

\section{2 太湖水体氮素污染的空间差异}

太湖作为一个大型浅水湖泊,连接 200 多条河流,包括较大河流几十条, 导致太湖水质存在很大的空间 
差异性 ${ }^{[22]} .1998-2006$ 年环太湖地区河流人湖水质平均浓度均为劣 V 类, 常州河流人湖水质最差, 无锡次 之, 苏州、湖州河流入湖水质较好, 直湖港、武进港、漕桥河、太滆运河、陈东河、南溪等河流入湖水质最差, 带人太湖 的污染物量较大. 太湖北部梅梁湾有主要人湖口梁溪河和直湖港, 来水流域多为平原和城镇地区, 工农业发达, 水 质差; 西南部多林地, 人口密度小, 城镇少, 水质相对较好; 南部地区的苕溪河是太湖的主要人湖河流之一; 东部 的太浦河是太湖的主要出水, 这样造成了南部湖区水流交换较快, 水质相对于北部较好 ${ }^{[23]}$. 张晓晴等 ${ }^{[24]}$ 的研 究表明, 2005-2007 年太湖水体 TN 浓度在梁溪河、直湖港、大浦口和竺山湾明显高于其他地区, 其中梁溪河 的 TN 平均值为 $6.892 \mathrm{mg} / \mathrm{L}$, 直湖港为 $5.379 \mathrm{mg} / \mathrm{L}$, 大浦口为 $6.758 \mathrm{mg} / \mathrm{L}$, 竺山湾为 $5.219 \mathrm{mg} / \mathrm{L}$, 而东部湖 区仅为 $2.772 \mathrm{mg} / \mathrm{L}$, 湖心区为 $2.981 \mathrm{mg} / \mathrm{L}$, 仅为人湖口的 $1 / 3$. 可见, 人湖污染源是造成太湖水质空间分布 差异的最主要原因. 朱广伟 ${ }^{[21]}$ 在分析了 2005-2007 年太湖不同湖区的营养盐数据后也发现太湖水体 TN 浓 度在人湖河口区明显高于其他湖区.

太湖水体中营养盐浓度的持续升高导致夏天蓝藻暴发以及在太湖西、北部水域大量聚集而出现水华. 水华吸收了水体中的可利用氮, 在风浪的影响下在局部区域堆积也会导致氮浓度产生区域差异. 邓建才 等 ${ }^{[25]}$ 的研究表明, 梅梁湾、竺山湾、贡湖湾、西岸区和湖心区水体中的总氮浓度显著高于其他湖区, 碎屑态氮 的空间分布规律与总氮基本一致,即总氮高的水体碎屑态氮的含量也高.

\section{3 太湖水体氮素污染的季节变化}

太湖水体中氮素污染不仅存在空间差异, 也存在季节差异性, 且湖体的水质变化季节特征与流域河道 一致. $\mathrm{Xu}$ 等 ${ }^{[15]}$ 的研究发现, 梅梁湾和湖心区不同形态氮浓度的变化趋势均是冬季升高, 夏季降低. 同样, 许 梅等 ${ }^{[26]}$ 对太湖人湖河流的观测也显示出冬、春季节氮含量高,夏、秋季氮含量相对低的特点.

冬、春季, 太湖水体氮浓度处于全年的高峰, 其原因一方面是冬、春季湖泊水位较低, 进入湖泊的营养盐 被浓缩; 另一方面是由于春季春耕农田大量施肥 ${ }^{[21]}$. 夏季湖水氮浓度降低一方面是由于夏季降雨量比较大, 湖泊水位较高, 使得营养盐得到一定程度的稀释 ${ }^{[15]}$; 另一方面主要是由于夏季高温季节反硝化作用引起水 体氮素损失 ${ }^{[27]}$. 雨季的到来也往往意味着污染物输人的高峰, 原因可能是太湖周围有无锡、苏州、常州和湖 州等城市, 城镇路面大部分是不透水地面, 由人类生活垃圾、生活污水及某些工业废水所携带的氮、磷营养 物易随地表径流进人太湖水体, 造成水体的氮源污染, 虽然氮污染的总量是增加的, 但绝对浓度并没有增 加, 降雨总体上还是以稀释作用为主.

\section{2 太湖水体氮素污染来源}

\section{1 太湖水体氮素的外源输入}

2.1 .1 入湖河道的输入 河流是湖泊与流域生态环境联结的主要纽带和通道, 尤其是入湖河流, 直接影响湖 泊的整体水质状况. 研究表明, 整个太湖出人湖河流水质状态以氮污染为主导因素 ${ }^{[28]}$. 据统计, 1980s 河道 $\mathrm{TN}$ 的输人量占人湖总量的比重为 $72.02 \%, 1990 \mathrm{~s} \mathrm{TN}$ 由河道的人湖量已占总量的 $90 \%$ 以上 ${ }^{[29]}$. 通过分析计 算, 2009-2010 年内太湖全年氮素河道输人总量约为 $7.00 \times 10^{4} \mathrm{t}$, 湖西区和浙西区环湖河道是太湖氮素的 主要来源, 其人湖量分别占河道总输人量的 $71.2 \%$ 和 $22.6 \%{ }^{[30]}$.

太湖外源氮污染中, 农业面源污染占的比重最大, 达 $56 \%{ }^{[31]}$; 其次是生活污水 $(<25.1 \%)^{[32-33]}$ 和养殖 污水 $(17.2 \% \sim 26.5 \%)^{[34]}$. 人工合成肥料(化肥) 的过量使用是农业营养盐产生量增加以及农业面源污染最 直接的原因. 在 $1970 \mathrm{~s}$ 至 1980s 初期间, 太湖流域有机肥与化肥的使用比例为 6:4, 但到 1980s 后期及 $1990 \mathrm{~s}$ 中期, 这一比例分别提高到 $3: 7$ 及 $1: 9^{[34]}$. 以无锡为例 ${ }^{[34]}$, 化肥投人对水稻、小麦产出增长的贡献额分别达 $10.3 \%$ 和 $34.9 \%$, 每年化肥使用量已由 $1980 \mathrm{~s}$ 中后期的 $25 \mathrm{~kg} / \mathrm{hm}^{2}$ 增加到 2000 年的 $45 \mathrm{~kg} / \mathrm{hm}^{2}$, 仅水稻田约 $12 \% \sim 17 \%$ 的氮素会随径流流失. 据李恒鹏等 ${ }^{[31]}$ 的研究, 太湖上游面源污染输人太湖的总氮量为 $7632 \mathrm{t} / \mathrm{a}$, 其中来自农业面源的为 $4289 \mathrm{t} / \mathrm{a}$, 占面源量的 $56.20 \%$. 太湖流域地表水中的主要污染物为铵态氮, 其中 $57 \%$ 的铵态氮都来自农业面源污染 ${ }^{[35]}$.

除农业污染外, 工业污水和生活污水也是太湖重要的污染来源. 目前, 太湖流域结构性污染十分严重, 化工、纺织印染、黑色冶金依然是重点污染行业. 由于乡镇企业的快速发展和布局的分散性、经营方式的多 变性及其初级粗加工, 造成的污染极为严重, 境内原本清澈的大小河道因大量工业废水的污染而变黑 ${ }^{[36]}$. 根 
据国家环境保护总局 “太湖水污染防治九 - 五计划及 2010 年规划” 的统计数据, 1994 年太湖地区人湖总氮 $30635 \mathrm{t}$, 其中工业污水占 $16 \%$, 即 $4902 \mathrm{t}$; 根据国家环境保护总局 “太湖水污染防治十 - 五计划”,2000 年太 湖流域工业污染排放 $\mathrm{NH}_{4}^{+}-\mathrm{N}$ 达 $6500 \mathrm{t}$, 占人湖总氮的 $5 \%$.

太湖流域城市化已超过 $51 \%$, 年生产生活污水已达 $50 \times 10^{8} \mathrm{t} / \mathrm{a}$, 而污水处理率不足 $20 \%{ }^{[17]}$. 以太湖流 域无锡市 ${ }^{[30]}$ 为例, 1980-2000 年生活用水总量从 $8.03 \times 10^{4} \mathrm{t} / \mathrm{d}$ 提高到 $30.1 \times 10^{4} \mathrm{t} / \mathrm{d}$; 同期生产用水量就从 1980 年的 $4116 \times 10^{4} \mathrm{t} / \mathrm{d}$ 增加到 2000 年的 $8519 \times 10^{4} \mathrm{t} / \mathrm{d}$, 而无锡市区城市污水处理率也仅 $42.9 \%(2000$ 年), 包括郊县在内的城镇生活污水处理率仅 $27.5 \%$. 根据许朋柱 ${ }^{[37]}$ 的估算, 全太湖流域城市系统在 2000 年的 $\mathrm{N}$ 排放量分别约为 $7.40 \times 10^{4} \mathrm{t}$, 而 1980 年的排放量约为 $3.31 \times 10^{4} \mathrm{t}$. 据李荣刚、熊正琴等估计 ${ }^{[32-33]}$ : 全 太湖流域每年生活污水带人水体的总氮量占 $25.1 \%$. 另外, 太湖地区农村用水量也在逐年上升, 由于大多农 村污水处理设施不健全, 没有完整的污水收集和处理设施, 大多农村生活污水未经处理就直接到处泼洒, 而 则所污水则直接或间接排人河道. 据史龙新等 ${ }^{[38]}$ 的调查, 在宜兴, 有 $24 \%$ 的农户生活废水选择了直接排人 村河, $50 \%$ 的农户排水采用排人屋后及地表渗人地下, $25 \%$ 的农户选择排人沟渠. 因此, 太湖上游地区农村 居民区河流水体铵态氮负荷也较高 ${ }^{[34]}$. “太湖水污染防治十 - 五计划” 中指出, 2000 年太湖流域城镇生活污 水 $\mathrm{NH}_{4}^{+}-\mathrm{N}$ 产生总量为 $2.34 \times 10^{4} \mathrm{t}$, 而农村生活污水 $\mathrm{NH}_{4}^{+}-\mathrm{N}$ 产生量为 $2.6 \times 10^{4} \mathrm{t}$. 而且, 夏季降雨和城镇人类 活动产生的污染物对太湖沉积物的硝态氮含量有较大影响 ${ }^{[39]}$.

随着渔业经济的迅速发展, 其对水体的氮素污染也逐步加剧. 许海等 ${ }^{[40]}$ 的研究也表明鱼塘养殖产生的 不仅是无机氮污染, 更严重的是产生了大量有机氮污染. 太湖地区的渔业发达, 每年因水产养殖带人水体中 的氮占总氮量的 $17.2 \% \sim 26.5 \%{ }^{[34]}$.

2.1 .2 大气沉降的输入 大气氮素的沉降也是极为重要的外源性因素 ${ }^{[41]}$. Galloway 等和 Holland 等 ${ }^{[42-43]}$ 指 出全球大气氮的沉降量已经达到 $10^{9} \mathrm{~kg} / \mathrm{a}$. 近年来国内学者逐渐认识到湖面大气沉降是重要污染来源 ${ }^{[44-46]}$. 宋玉芝等对 2002 年 7 月一 2003 年 6 月大气降水的研究 ${ }^{[47]}$ 表明, 太湖流域大气降水已呈富营养化水质的特 征, 每年由湿沉降直接进人太湖水体的 TN 约为 $6562.2 \mathrm{t}$, TN 占人湖河道年输人污染物总量的 $13.6 \%$, 大气 湿沉降中, TIN 对 TN 的贡献比较大, 平均约为 $78.78 \%$.

1990s 以来, 太湖大气湿沉降的总量不断升高. 杨龙元等 ${ }^{[48]}$ 的研究表明, 2002-2003 年太湖水体大气 $\mathrm{TN}$ 沉降率为 $4226 \mathrm{~kg} /\left(\mathrm{km}^{2} \cdot \mathrm{a}\right)$, TN 的大气年沉降负荷为 $9881 \mathrm{t} / \mathrm{a}$, 湿沉降中的 TN 为 $7852 \mathrm{t} / \mathrm{a} . \mathrm{Xie}$ 等 $^{[49]}$ 指 出 2003-2005 年大气湿沉降中 $N$ 的年均沉降量为 $2700 \mathrm{~kg} / \mathrm{km}^{2}$. 罗潋苟等 ${ }^{[50]}$ 研究了湿沉降对太湖氮、磷营 养盐输人的影响及其时间和空间的差异性, 结果表明湿沉降占太湖外源氮输人的 $16.5 \%$, 其中主要集中在 太湖的北部和东部, 季节上春、夏季要明显高于秋、冬季. 2009-2010 年大气湿沉降中 TN 的年沉降量为 $10868 \mathrm{t}$, 为同期河流人湖负荷的 $18.6 \%$, 可见湿沉降对太湖富营养化的贡献不容忽视 ${ }^{[51]}$.

\section{2 太湖水体氮素污染的内源输入}

输人湖泊水体的营养性污染物一部分会经过物理、化学和生物过程累积在沉积物中成为湖泊氮素内负 荷的源 ${ }^{[52]}$. 在外源性污染得到有效控制以后, 内源性污染成为湖泊发生富营养化的关键因素. 对于太湖这样 一个浅水湖泊而言,除了外源营养盐的输人之外, 湖泊底泥所造成的内源释放也是一个重要原因 ${ }^{[53]}$.

2.2 .1 内源氮的释放形式 关于太湖的内源释放, 目前主要关注的是底泥释放问题, 其释放形式主要有静态 释放和动态释放两种. 沉积物在没有风浪的情况下营养盐的释放主要依靠从沉积物孔隙水中与上覆水中的 营养盐浓度差而释放, 当风浪较小、不足以悬浮扰动水土界面的情况下, 沉积物的营养盐释放将由于水柱复 氧而略有下降, 当风浪较大, 导致沉积物悬浮的情况下, 沉积物中的营养盐将伴随沉积物的悬浮而大幅度释 放, 水柱的颗粒物和溶解性的营养盐浓度在短期内会有所增加, 但是当动力扰动撤除后, 颗粒态的营养盐又 沉人湖底, 埋在沉积物中的有机颗粒物质继续降解析出, 并按照静态释放的规律进人上覆水. 当下一次大风 浪来临时, 又按照动态释放的规律而释放.

铵态氮是氮素内源释放的主要形态, 其释放程度与溶氧量呈负相关, 与温度呈正相关 ${ }^{[54]}$, 主要有两种来 源: 一是湖泊内部异养生物矿化、分解有机物再生; 二是在厌氧环境中反硝化细菌通过反硝化作用将硝态 氮、亚硝态氮转化为铵态氮.

在沉积环境中, 含氮有机物在戻氧的环境条件下通过微生物的矿化、分解作用转变成铵态氮, 然后, 进 
人孔隙水, 再进一步通过分子扩散和浓度梯度扩散重新进人湖泊水体中 ${ }^{[55]}$. 研究表明: 沉积物在氧化条件 下, 通过厌氧微生物作用, 将有机质分解和矿化, 可产生大量 $\mathrm{NH}_{4}^{+}-\mathrm{N}$ 进人孔隙水 ${ }^{[56]}$. 这一过程主要取决于含 氮有机物分解的难易程度, 主要与 $\mathrm{O}_{2}$ 含量、氧化还原电位、沉积物中 $\mathrm{C} / \mathrm{N}$ 比值、阳离子交换量、温度、生物扰 动、细菌的作用等有关. 太湖是一个大型浅水湖泊, 太湖底泥虽然较薄, 对氮素的吸附、聚集能力却较强, 风 浪会导致底泥扰动, 频繁的动力悬浮使得沉积物表层的数厘米或数十厘米的底泥发生悬浮, 底泥孔隙水中 的营养盐也因此得以释放 ${ }^{[55]}$. 对铵态氮而言, 悬浮作用 (悬浮 + 扩散) 造成的上覆水营养盐浓度增加可以达 到单纯由扩散产生的营养盐浓度的数十倍 ${ }^{[57]}$.

此外, 死亡的浮游植物可被细菌和浮游动物重新矿化, 或者自溶产生溶解性有机氮, 再被细菌降解为 $\mathrm{NH}_{4}^{+}-\mathrm{N}^{[58]}$. 太湖蓝藻水华期间, 蓝藻容易在局部大量堆积、腐烂. 朱梦圆等 ${ }^{[59]}$ 的研究表明, 上覆水 $\mathrm{NH}_{4}^{+}-\mathrm{N}$ 浓 度升高, 可能是由于藻类死亡后残体堆积分解, 本身氮含量造成了水体氮浓度增加. 而且, 厌氧条件下, 硝化 作用减弱, $\mathrm{NH}_{4}^{+}-\mathrm{N}$ 的消耗减少, 反硝化作用增强, $\mathrm{NO}_{3}^{-}-\mathrm{N}$ 或 $\mathrm{NO}_{2}^{-}-\mathrm{N}$ 可转化为 $\mathrm{NH}_{4}^{+}-\mathrm{N}$ 或 $\mathrm{N}_{2}{ }^{[60]}$. 另外, 包括藻 类、浮游动物和底栖生物在内的生物代谢也促使部分营养盐以溶解态形式直接释放进人水体, 同时生物残 体与粪便等颗粒物质的降解也使颗粒有机物再生为铵态氮.

2.2.2 内源氮的释放通量 浅水湖泊的内源释放量是国内外均无明确定论的一个问题, 它不同于深水湖泊 靠浓度梯度释放营养物质. 有关太湖的内源释放问题, 目前的工作主要集中在实验室的静态释放方面或者 是假定条件下的营养盐释放估算. 在实验室进行静态模拟实验, 采集太湖水域未受扰动的底泥柱样, 去除藻 类及悬浮物后加人 $30 \mathrm{~cm}$ 的水柱 (以不扰动沉积物表面为要求), 保持采样时的水体温度, 避光培养, 定时采 样测定上清液中的营养盐浓度, 估算出在静态条件下, 太湖全湖一年的 $\mathrm{NH}_{4}^{+}-\mathrm{N}$ 释放量达 $1 \times 10^{4} \mathrm{t}$ 左右 ${ }^{[61]}$. 在动态释放条件下, 动力扰动导致的释放量目前仍有争议. 秦伯强等 ${ }^{[61]}$ 根据室内动力扰动摸拟实验和太湖 的风速分布频率, 估算出太湖每年约有 $8 \times 10^{4} \mathrm{t}$ 的总氮从沉积物释放至水体中. 但这种估算只反映了底泥的 悬浮量, 没有考虑颗粒物的沉降部分, 导致估算结果偏高. 逢勇等 ${ }^{[62]}$ 根据太湖沉积物再悬浮通量与风速的相 关关系, 对太湖年均内源氮素释放量进行估算, 结果表明太湖内源总氮年释放量只有约 $7700 \mathrm{t}$, 为外源输人 的 $25.7 \%$.

浮游植物能直接利用的氮素主要是溶解性的 $\mathrm{NH}_{4}^{+} 、 \mathrm{NO}_{3}^{-}$、尿素和其它小分子的有机氮. 目前, 风浪扰动 情况下太湖内源氮的释放主要是对包括底泥颗粒物在内的总氮释放量进行估算, 关于这些释放量能有多少 比例可以被浮游植物利用还不清楚, 尤其是颗粒物在水体中停留期间的矿化分解速率值得重视. 虽然对于 太湖内源释放量存在一定的争议, 但其对太湖氮素污染的重要贡献是不容忽视的. 太湖内源产生的 $\mathrm{NH}_{4}^{+}-\mathrm{N}$ 能否满足蓝藻水华的氮需求,维持蓝藻的持续发生,还需要做深人的研究.

\section{3 太湖水体氮素的迁移转化及氮素平衡}

氮素的迁移转化是一个包括物理、化学和生物作用的复杂过程. 氮在湖泊水体中的迁移主要指可溶性 氮或颗粒氮受水体水动力特性的影响, 以紊动涡漩的水团运动形态与水体进行交换, 从而得到扩散的过程. 氮在湖泊水体中的转化过程主要包括生物固氮、氮的吸收同化、氨化作用、硝化作用及反硝化作用, 这一过 程与水体中微生物、藻类和高等水生植物等的种类和数量密切相关 ${ }^{[63]}$.

\section{1 生物固氮}

生物固氮指固氮微生物将大气中的 $\mathrm{N}_{2}$ 还原成 $\mathrm{NH}_{4}^{+}-\mathrm{N}$ 的过程 (图 1). 此过程在常温常压下进行, 必须要 有固氮酶的催化, 目前自然界仅原核生物中的根瘤菌、放线菌和一部分具有固氮能力的蓝藻. 在没有人为干 扰的情况下, 生物固氮是补偿湖泊浮游植物氮需求的重要途径. Schindler 等 ${ }^{[64]}$ 根据加拿大实验湖区 227 号 湖 $37 \mathrm{a}$ 的大规模实验结果, 认为当水中富磷而缺氮时, 会出现具有固氮功能的蓝藻, 固氮作用可以弥补浮游 植物生长过程中缺少的氮, 并由此提出控氮措施不能有效控制富营养化的观点. 然而, 很多研究表明, 由蓝 藻固氮作用输人到水生态系统中的氮, 远不足浮游植物氮需求的 $50 \%{ }^{[9,65]}$. 除了氮磷比外, 还有很多因子控 制这个耗能的固氮过程 ${ }^{[66]}$. 太湖夏季形成水华的蓝藻主要是没有固氮能力的微囊藻, 能固氮的鱼腥藻只在 早春季节出现, 关于太湖水体是否存在固氮作用, 其对湖泊氮素输人的贡献有多大, 目前的研究较少. 根据 张波的研究 ${ }^{[67]}$, 太湖水体年固氮量只占外源 TN 输人量的 $0.11 \%$, 说明目前太湖水体的生物固氮作用较弱, 
对氮素输人的贡献很小.

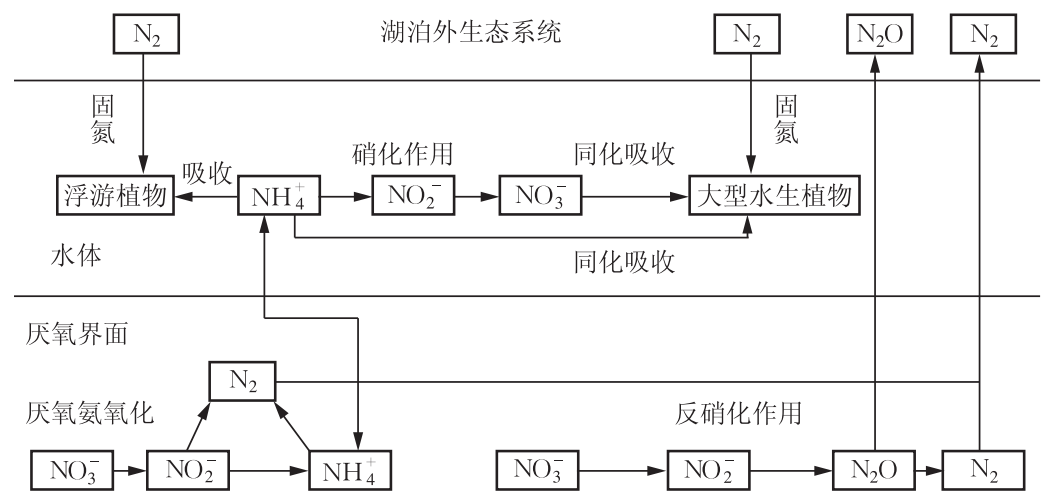

图 1 湖泊生态系统中氮素转化示意图

Fig. 1 Conceptual diagram of the transformation of nitrogen in the lake ecosystem

\section{2 氮的吸收同化}

湖泊中的藻类、高等水生植物、底栖动物等能将氮素转化为自身生物量, 经人工捞取或收获后离开湖泊 生态系统( 图 1).

藻型湖泊生态系统中, 浮游藻类占优势地位, 可食性藻类的生物量被浮游动物和鱼类捕食, 最后通过渔 获物输出湖体. 但富营养化湖泊的优势浮游藻类为食用价值比较低的蓝藻, 所以正常的食物链遭到破坏, 湖 泊生态系统的氮营养物质循环发生改变. 湖泊处于草型清水状态时, 湖泊生态系统具有完整的食物链结构. 大型水生植物通过自身对氮营养元素进行吸收同化、收获输出、沉积输出等过程, 使氮素脱离湖泊内的营养 循环.

太湖具有藻型湖区和草型湖区共存的生态特征. 藻型湖区的蓝藻主要通过在无锡、宜兴和常州武进区 沿太湖岸线下风区设置打捞站进行打捞, 这样不仅有效防止蓝藻水华堆积死亡造成的水体污染, 也将大量 蓝藻吸收的氮素从水体去除, 有效降低水体的氮素污染. 根据江苏省水利厅的数据,2011 年共从太湖打捞蓝 藻 $97 \times 10^{4} \mathrm{t}$, 相当于直接从湖体取出氮 $500 \mathrm{t}$.

\section{3 硝化作用}

微生物能将氨氧化为硝酸盐, 这个过程称为硝化作用 (图 1). 硝化作用可分为两个连续而又独立的阶 段, 即由亚硝化菌完成氨氧化的亚硝酸盐阶段和由硝化菌完成的亚硝酸盐氧化的硝酸盐阶段. 硝化作用是 需氧反应, 受溶解氧含量、微生物的繁殖和硝化活性等因素制约 ${ }^{[68]}$. 湖泊中硝化作用最重要和最强烈的地点 是有氧沉积物, 原因是沉积物上表层存在大量的硝化细菌 ${ }^{[69]}$, 但是在 $\mathrm{NH}_{4}^{+}-\mathrm{N}$ 浓度较高的富营养化湖泊水体 中, 同样也具有较高的硝化速率. 目前关于太湖硝化作用的研究主要涉及硝化细菌的分布及铵态氮浓度对 硝化作用的影响 ${ }^{[70-72]}$, 而其它方面较少, 尤其是硝化作用对于铵态氮释放量的影响需要深人研究.

\section{4 反硝化作用}

反硝化作用是指硝态氮和亚硝态氮在无氧或低氧条件下, 被微生物还原转化为 $\mathrm{N}_{2}$ 的过程 (图 1 ). 反硝 化作用是厌氧反应, 只有当氧气浓度足够低时才会发生, 但并不是氧的分压越低越好, 而应保持一定的含氧 量 $^{[68]}$. 反硝化作用主要在沉积物中进行, 通过沉积物厌氧层内的反硝化作用, 可以以 $\mathrm{N}_{2} \mathrm{O} 、 \mathrm{~N}_{2}$ 等气体形态去 除内源氮负荷. 反硝化速率与上覆水中的 $\mathrm{NO}_{3}^{-}-\mathrm{N}$ 浓度呈正比. 徐辉等 ${ }^{[73]}$ 的研究发现, 梅梁湾内及湾外开敞 湖区的水土界面反硝化脱氮速率为 $(6.34 \pm 22.74) \sim(46.36 \pm 13.26) \mu \mathrm{mol} /\left(\mathrm{m}^{2} \cdot \mathrm{h}\right)$, 梅梁湾北部河口区水 土界面总脱氮能力明显高于梅梁湾南部及开敞湖区.

在蓝藻水华暴发的水体中, 藻团内形成的好氧一缺氧的微环境, 以及蓝藻衰亡过程中的分解产生大量的 有机物, 加剧了水体中溶解氧的消耗, 导致水体中氧化还原电位大幅度下降. 较低的氧化还原电位, 将有利 于微生物反硝化作用的进行, 使水体中氮素赋存数量降低. 所以, 对蓝藻水华暴发和衰亡过程中硝化和反硝 
化能力进行定量研究,将有利于阐明蓝藻水华暴发对水体氮素迁移转化的影响.

\section{5 厌氧氨氧化}

厌氧氨氧化是指厌氧氨氧化细菌在厌氧条件下以亚硝酸盐为电子受体将铵态氮氧化为氮气的过程 (图 1). 之前人们一直认为反硝化是水生态系统中 $\mathrm{N}_{2}$ 产生和沉积物中氮素去除的唯一方式. 1995 年, Mulder 等 ${ }^{[74]}$ 在荷兰某公司处理工业废水的中试流化床中发现铵态氮的消失与亚硝酸的消失同时发生, 且呈一定的 比例, 他们认为反应器内铵态氮与亚硝酸盐同时发生反应, 产物为 $\mathrm{N}_{2}$, 并将此命名为厌氧氨氧化, 这是第一 次发现厌氧氨氧化过程. 目前, 对影响厌氧氨氧化环境因素的了解还很少, 其中, 沉积物矿化速率是最重要 的因素, 其次是 $\mathrm{NO}_{3}^{-}$浓度、有机质含量、厌氧氨氧化菌的生长状况等. 当 $\mathrm{NH}_{4}^{+}$浓度较低时, 厌氧氨氧化菌将 与硝化细菌以及同化吸收 $\mathrm{NH}_{4}^{+}$的藻类共同竞争 $\mathrm{NH}_{4}^{+}$, 所以厌氧氨氧化过程可能会受到限制. 目前, 厌氧氨 氧化是海洋环境中研究的热点, 许多文献报道海洋中沉积物的厌氧氨氧化脱氮在反硝化过程中所占的比例 最多可超过 $50 \%$, 对海洋氮的去除起着很重要的作用 ${ }^{[75-76]}$. 在湖泊中厌氧氨氧化方面的研究还很少, Schubert 等 ${ }^{[77]}$ 首先在湖泊生态系统中发现了该过程. 由于海洋和湖泊存在一定的相似性, 而且厌氧氨氧化菌可 能会随环境的变化而进行变异, 所以在高浓度 $\mathrm{NH}_{4}^{+}$和厌氧环境普遍存在的富营养化湖泊中, 厌氧氨氧化过 程对水体脱氮是否同样具有十分重要的作用值得研究. 徐徽等 ${ }^{[73]}$ 研究表明, 太湖梅梁湾厌氧氨氧化脱氮比 例占总脱氮比例的 $12 \% \sim 14 \%$, 湾外开敞湖区则占 $11 \%$, 但其发生过程具体受到哪些因子的影响还需要进 一步研究.

\section{6 太湖水体氮素的平衡}

湖泊水体中氮素的输人主要通过上述的点源、面源和内源方式. 湖泊生态系统中氮素的输出方式有 3 种, 一是通过常规反硝化或厌氧氨氧化作用生成 $\mathrm{N}_{2}$ 或 $\mathrm{N}_{2} \mathrm{O}$ 后从水体去除; 二是被沉积物吸附, 或通过沉积 作用进人沉积物并固定下来; 三是被藻类或者大型水生植物等同化吸收后, 随食物链流动, 最后部分氮素通 过人工方式 (鱼类捕捞和蓝藻打捞) 输出, 前 2 个途径属湖泊氮素自净作用.

许朋柱等 ${ }^{[78]}$ 根据 $2001-2002$ 水文年 115 条环太湖河道的环境监测资料, 估算 TN 人湖通量为 $28658 \mathrm{t} / \mathrm{a}$, 出湖通量为 $14600 \mathrm{t} / \mathrm{a}$, 入湖通量超过出湖通量约 1 倍, 但并没有分析出人湖通量差异是完全滞留 在湖内, 还是通过其它途径脱离湖体. 胡开明等 ${ }^{[79]}$ 的研究表明, 2007-2010 年环太湖河流总氮年均人湖量 为 $3.7 \times 10^{4} \mathrm{t}$, 其中夏季环太湖总氮输人约为 $1.12 \times 10^{4} \mathrm{t}$, 为一年中汇人量最大的季节; 氮素出湖量为 $1.89 \times$ $10^{4} \mathrm{t}$, 人湖量大于出湖量, 说明太湖对河流汇入的氮营养盐有明显的削减作用. 其认为, 削减作用主要原因一 方面是太湖水资源利用等的消耗, 另一方面是太湖水动力强度较弱, 河流中以颗粒态形式存在的氮营养盐 流人太湖后, 会发生沉降作用. 陈小锋等 ${ }^{[30]}$ 对 2009-2010 水文年环太湖 25 条主要河流及太湖梅梁湾、东太 湖等典型区域的各形态氮素进行分析, 并利用太湖出人湖水量、蓝藻人工打捞量和鱼产量等相关数据, 分析计 算太湖氮素流动和转化潜力, 发现太湖全年河道氮素人湖量约为 $7 \times 10^{4} \mathrm{t}$, 出湖量约为 $4.01 \times 10^{4} \mathrm{t}$; 整个水文年 中, 太湖氮素自净量约为 $3.22 \times 10^{4} \mathrm{t}$, 其中约 $3.02 \times 10^{4} \mathrm{t}$ 氮素是通过反硝化途径去除的, 体现出湖泊强大的 氮素自净能力.

\section{4 结语}

氮素是水生生物必需的营养盐, 但过量的氮营养盐也是导致水体富营养化的重要原因. 水体中氮营养 盐的升高一般通过外源输人和内源释放两种作用方式. 外源输人主要是通过人湖河流等将农田、生活和工 业等含氮废水输人湖中, 直接引起水体中氮营养盐的升高; 而内源释放是由沉积物中的有机氮经过矿化分 解作用转化为无机氮, 通过沉积物中的空隙进人上覆水, 从而引起水体中氮营养盐的升高.

目前为止, 对太湖氮素外源输人的控制已经取得一定的成果, 但要彻底消除水体污染尚有距离. 而这方 面, 难点是需要寻找双赢的方法, 既要保证经济的发展, 又不破坏自然水体. 例如, 农业面源污染方面, 采取 何种施肥方式才能做到既保证农业生产的需要又不污染土壤和水体, 这需要各领域专家的共同努力.

太湖营养盐的内源释放是近几年的研究热点, 因其释放具有一定的时间和空间差异, 内源的补给为太 湖富营养化的治理带来了很大的困难. 内源中的氮素补给主要是通过铵态氮的再生过程, 它是氮素循环中 的重要环节, 在沉积环境和水体中均可以发生, 对浮游植物氮素的短期供给具有重要作用, 对水体的营养状 
态和水质具有重要的影响, 但对于其具体的释放量, 仍存在一定的争议. 目前估算的内源营养盐释放量只是 估算了其在静态或者动态条件下从沉积物中释放出的总量, 释放出的营养盐有大部分还是会沉淀到沉积物 中, 而通过动态或者静态条件释放出的营养盐到底有多少能真正被植物利用, 这一问题涉及了浅水湖泊营 养盐的迁移、转化过程及生态效应方面的研究, 即内源释放的营养盐对水华暴发的刺激程度, 至今, 我们对 这方面了解较少,有待进行深人研究帮助我们揭示蓝藻暴发的机理.

氮素在水体中处于动态平衡状态, 太湖的氮素主要通过连接太湖的 200 多条河道输人和输出, 其中湖 西区的河道是氮素的主要输人途径, 而氮素的输出主要通过湖泊东部区域河道. 大量的氮素进人水体以后, 会通过沉降作用汇人到湖底沉积物中, 而存在于水中的氮素主要以反硝化的方式被去除. 太湖氮素的输人 量与输出量虽然有较多数据, 但各研究所用的计算与统计方法相差较远, 计算结果相差较大, 使得关于湖泊 氮素输人、输出负荷数据不统一, 对湖泊治理造成不便. 对于湖泊氮素的输人与输出的计算需要我们进一步 研究, 确定统一的计算方法, 从而为治理太湖提供更有力的科学依据.

\section{5 参考文献}

[ 1 ] 孔繁翔,高 光. 大型浅水富营养化湖泊中蓝藻水华形成机理的思考. 生态学报,2005,25(3):589-595.

[2] 黄智华, 薛 滨, 逢 勇. 太湖水环境演变与流域经济发展关系及趋势. 长江流域资源与环境, 2006, 15(5): $15-23$.

[ 3 ] Schindler DW. Eutrophication and recovery in experimental lakes: Implications for lake management. Science, 1974, 184: 897-899.

[ 4 ] Conley DJ, Humborg C, Rahm L et al. Hypoxia in the Baltic Sea and basin-scale changes in phosphorus biogeochemistry. Environ Sci Technol, 2002, 36:5315-5320.

[ 5 ] Schindler M. Evolution of phosphorus limitation in lakes. Science, 1977, 195: 260-262.

[ 6 ] Temponeras M, Kristiansen J, Moustaka-Gouni E. Seasonal variation in phytoplankton composition and physicl-chemical features of the shallow lake Doirani, Macedonia, Greece. Hydrobiologia, 2000, 424: 109-122.

[ 7 ] Levine SN, Schindler DW. Influence of nitrogen to phosphorus supply ratios and physicochemical conditions on cyanobacteria and phytoplankton species composition in the experimental lakes Area, Canada. Can J Fish Aqua Sci, 1999, 56: $451-466$.

[ 8 ] Nalewajko C, Murphy T. Effect of temperature, and availability of nitrogen and phosphorus on the abundance of Anabaena and Microcysis in Lake Biwa, Japan: an experimental approach. Limnology, 2001, 2 : 45-48.

[ 9 ] Lewis WM, Wurtsbaugh AW. Control of lacustrine phytoplankton by nutrients: Erosion of the phosphorus paradigm. Internat Rev Hydrobiologia, 2008, 93 : 446-465.

[10] Suttle CA, Harrison PJ. Rapid ammonium uptake by freshwater phytoplankton. Journal of Phycology, 1988,24:13-16.

[11] 陈 军,权文婷, 孙记红. 太湖氮磷浓度与水质因子的关系. 中国环境监测, 2011,27(3):79-83.

［12］张 瑛. 柴窝堡湖富营养化和限制因子分析及富营养化防治对策. 干旱环境监测, 2011,25(3) : 160-166.

[13] 杨宏伟, 高 光, 朱广伟. 太湖章湖冬季浮游植物群落结构特征与氮磷浓度关系. 生态学杂志, 2012,31(1):1-7.

[14] 秦伯强. 太湖生态与环境若干问题的研究进展及其展望. 湖泊科学, 2009,21(4): 445-455.

[15] Xu H, Paerl HW, Qin BQ et al. Nitrogen and phosphorus inputs control phytoplankton growth in eutrophic Lake Taihu, China. Limnology and Oceanography, 2010, 55: 420-432.

[16] 张运林,秦伯强. 太湖水体富营养化的演变及研究进展. 上海环境科学, 2001,20(6):263-265.

[17] 孙顺才, 黄渏平. 太湖. 北京: 海洋出版社, 1993:23-89.

[18] 林泽新. 太湖流域水环境变化及缘由分析. 湖泊科学,2002,14(2):97-103.

[19] 朱广伟. 太湖富营养化现状及原因分析. 湖泊科学,2008,20(1):21-26.

[20] 成 刚. 太湖氮营养盐的分布特征及区域差异性研究 [ 学位论文]. 苏州: 苏州大学, 2010 .

[21] 朱广伟. 太湖水质的时空分异特征及其与水华的关系. 长江流域资源与环境,2009,18(5):439-445.

[22] 秦伯强,胡维平,陈伟民等. 太湖水环境演化过程与机理. 北京:科学出版社,2004.

[23] 朱广伟, 高 光,秦伯强等. 浅水湖泊沉积物中磷的地球化学特征. 水科学进展, 2003,14(6): 715-719.

[24] 张晓晴,陈求稳. 太湖水质时空特性及其与蓝藻水华的关系. 湖泊科学, 2011,23(3):339-347.

[25] 邓建才,陈 娇, 霍水晶等. 太湖水体中氮、磷空间分布特征及环境效应. 环境科学, 2008,29(12) : 3382-3386. 
[26] 许 梅, 任瑞丽, 刘茂松. 太湖人湖河流水质指标的变化规律. 南京林业大学学报: 自然科学版, 2007,31 (6): 121-124.

[27] McCarthy MJ, Lavrentyev PL, Yang L et al. Nitrogen dynamics relative to microbial food web structure in a subtropical, shallow, well-mixed, eutrophic lake. Hydrobiologia, 2007, 581 : 195-207.

[28] 余 辉,燕姝雯,徐 军. 太湖出人湖河流水质多元统计分析. 长江流域资源与环境, 2010,19:696-702.

[29］李一平,逢 勇,李 勇. 水动力作用下太湖底泥的再悬浮通量. 水利学报,2007,38(5):558-564.

[30] 陈小锋,揣小明,曾 巾等. 太湖氮素出入湖通量与自净能力研究. 环境科学, 2012,33(7):2309-2314.

[31］李恒鹏,杨桂山, 黄文钰. 太湖上游地区面源污染氮素人湖量模拟研究. 土壤学报,2007,44(6):1063-1069.

[32] 李荣刚,夏源陵, 吴安之等. 江苏太湖地区水污染物及其向水体的排放量. 湖泊科学,2000,12(2):147-153.

[33] 熊正琴,邢光喜,沈光裕等. 太湖地区湖、河和井水中氮污染状况的研究. 农村生态环境, 2002,18(2): 29-33.

[34] 许 刚,朱振国,黄建光等. 无锡市社会经济发展对水环境的影响. 湖泊科学,2002,14(2):173-179.

[35] 胡必涁. 太湖流域水污染对太湖水质的影响分析. 上海环境科学,2003,22(12):1017-1021.

[36] 刘荣增, 朱继业, 张京祥等. 苏州市经济持续发展过程中的资源与环境问题透析. 长江流域资源与环境,2001,10 (4) :289-295.

[37] 许朋柱. 太湖流域 $N 、 P$ 营养盐的来源、排放及输运研究 [ 学位论文]. 南京: 中国科学院南京地理与湖泊研究 所, 2007.

[38］史龙新,李向阳,王 宁等.太湖地区农村面源污染控制技术与对策. 中国水利,2006,17:11-13.

[39] Townsend-Small A, McCarthy MJA, Yang LY et al. Stable isotopic composition of nitrate in Lake Taihu, China, and major inflow river. Hydrobiologia, 2007, 58(1): 135-140.

[40］许 海,刘兆普,焦佳国等. 太湖上游不同类型过境水氮素污染状况. 生态学杂志, 2008,27(1):43-49.

[41] HANS WP. Coastal eutrophication and harmful algal blooms: Importance and groundwater as "new" nitrogen and other nutrient sources. Limnology and Oceanography, 1997, 42(5, part 2) : 1154-1165.

[42] Galloway JN, Dentener FJ, Gapone DG et al. Nitrogen cycles: past, present, and future. Biogeochemistry, 2004,70 : 153-226.

[43] Holland EA, Dentener FJ, Braswell BH et al. Contemporary and pre-industrial global reactive nitrogen budgets. Biogeochemistry, 1999, 46: 7-43.

[44] 叶雪梅, 郝吉明, 段 雷等. 中国主要湖泊营养氮沉降临界负荷的研究环境污染与防治. 湖泊科学, 2002, 14 (1): 54-58.

[45］张修峰,李传红. 大气氮沉降及其对惠州西湖水体富营养化的影响. 中国生态农业学报,2008,16(1):16-19.

[46] 翟水晶, 杨龙元, 胡维平. 太湖北部藻类生长旺盛期大气氮、磷沉降特征. 环境污染与防治, 2009,31(4):5-10.

[47] 宋玉芝,秦伯强, 杨龙元等. 大气湿沉降向太湖水生生态系统输送氮的初步估算. 湖泊科学, 2005,17 (3):226-230.

[48］杨龙元,秦伯强,胡维平等. 太湖大气氮、磷营养元素干湿沉降率研究. 海洋与湖沼, 2007,38(2) : 104-110.

[49] Xie YX, Xiong ZQ, Xing GX et al. Source of nitrogen in wet deposition to a rice agroecosystem at Lake Taihu region. Atmospheric Environment, 2008, 42 : 5182-5192.

[50] Luo LC, Qin BQ, Song YZ et al. Seasonal and regional variations in precipitation chemistry in the Lake Taihu Basin, China. Atmospheric Environment, 2007, 24 : 2674-2679.

[51] 余辉, 张璐璐, 燕姝雯等. 太湖氮磷营养盐大气湿沉降特征及人湖贡献率. 环境科学研究, 2011, 24 (11): 1210-1219.

[52] 姜 霞,王秋娟,王书航等. 太湖沉积物氮磷吸附/解吸特征分析. 环境科学, 2011,32(5):1285-1291.

[53] Granli W. Internal phosphorus loading in Lake Ringsjn. Hydrobiologia, 1999, 4(4) :19-26.

[54] 王 政, 赵 林, 李 釒等. 不同时间尺度下湖泊氮素内源释放强度影响因素的研究. 农业环境科学学报, 2011,30 (12) :2542-2547.

[55］秦伯强,范成新. 大型浅水湖泊内源营养盐释放的概念性模式探讨. 中国环境科学, 2002,22(2): 150-153.

[56] 孙 英,何 江, 吕昌伟等. 岱海表层沉积物中影响铵态氮释放的模拟研究. 农业环境科学学报, 2009, 28 (7): 1464-1468.

[57] Reddy KR, Fisher MM, Ivanoff D. Resuspension and diffusive flux of nitrogen and phosphorus in a hypereutrophic lake. Journal of Environmental Quality, 1996, 25 :363-371.

[58] Golteman HL. The chemistry of phosphate and nitrogen compounds in sediments. London: Kluwer Academic Publishers, 
2004 : 135-180.

[59] 朱梦圆,朱广伟,王永平. 太湖蓝藻水华衰亡对沉积物氮、磷释放的影响. 环境科学,2011,32(2):409-415.

[60] 李 霖, 白 洁, 高会旺等. 长江口海域夏季沉积物反硝化细菌数量及反硝化作用. 中国环境科学, 2009,29(7): $756-761$.

[61] 秦伯强, 朱广伟, 张 路等. 大型浅水湖泊沉积物内源营养盐释放模式及其估算方法一一内湖为例. 中国科学: D 辑: 地球科学, 2005,35 (增刊 II) : 33-44.

[62] 逢 勇,颜润润,余钟波等. 风浪作用下的底泥悬浮沉降及内源释放量研究. 环境科学,2008,29(9):2456-2464.

[63] Ostroumov SA. Polyfunctional role of biodiversity in processes leading to water purification: current conceptualizations and concluding remarks. Hydrobiologia, 2002, 49(1/2/3) : 203-204.

[64] Schindler DW, Hecky RE, Findly DL et al. Eutrophication of lakes cannot be controlled by reducing nitrogen input: Results of a 37-year whole-ecosystem experiment. PNAS, 2008, 105(32) : 11254-11258.

[65] Paerl HW. Physiological ecology and regulation of $\mathrm{N}_{2}$ fixation in natural waters. Adv Microb Eco, 1990,11 : $305-344$.

[66] Forbes MG, Doyle RD, Scott JD et al. Physical factors control phytoplankton production and nitrogen fixation in eight Texas reservoirs. Ecosystems, 2008, 11:1181-1197.

[67] 张 波. 太湖水体和沉积物固氮速率及其影响因素 [学位论文]. 南京: 中国科学院南京地理与湖泊研究所,2012.

[68] Martin TL, Kaushik NK, Trevors JT et al. Review: denitrification in temperate climate riparian zones. Water, Air, and Soil Pollution, 1999, 111(1/2/3/4) : 171-186.

[69] Pauer JJ, Auer MT. Nitrification in the water column and sediment of a hypereutrophic lake and adjoining river system. Water Research, 2000, 34(4) : 1247-1254.

[70] 曾 巾, 杨柳燕, 肖 琳等. 太湖不同湖区乌无机氮转化潜力. 生态与农村环境学报,2008,24(1):63-67.

[71] 王国祥, 誉培民, 黄宜凯等. 太湖反硝化、硝化、亚硝化及氨化细菌分布及其作用. 应用与环境生物学报, 1998, 5 (2) : 190-194.

[72] 陈国元. $\mathrm{NH}_{3}-\mathrm{N}$ 浓度对太湖竺山湾水体及沉积物中硝化作用的影响. 水生态学杂志, 2012,33(2):55-59.

[73] 徐 徽, 张 路, 商景阁等. 太湖梅梁湾水土界面反硝化和厌氧氨氧化. 湖泊科学, 2009,21(6):775-781.

[74] Mulder A, Van de Graaf AA, Robertson A et al. Anaerobic ammonium oxidation discovered in a denitrifying fluidized bed reactor. FEMS Microbiol Ecol, 1995 ,16: 177-183.

[75] Rysgaard S, Glud RN, Risgaard-Petersen N et al. Denitrification and anammox activity in Arctic marine sediment. Limnology and Oceanography, 2004, 49(5) : 1493-1502.

[76] Engstron P, Dalsgaard T, Hulth $\mathrm{S}$ et al. Anaerobic ammonium oxidation by nitrite( anammox): Implications for $\mathrm{N}_{2}$ production in coastal marine sediments. Geochimica et Cosmochimica Acta, 2005, 69( 8) : 2057-2065.

[77] Schubert CJ, Durise-Kaiser E, Wehrli B et al. Anaerobie ammonium oxidation in a tropical freshwater system( Lake Tanganyika). Environmental Microbiology, 2006, 8(10): 1863-1875.

[78] 许朋柱, 秦伯强. 2001-2002 水文年环太湖河道的水量及污染物通量. 湖泊科学, 2005,17(3):213-218.

[79］胡开明,逢 勇, 王 华. 太湖湖体总氮平衡及水质可控目标. 水科学进展, 2012,23(4):555-562. 